\title{
BMJ open ANRS-COM'TEST: description of a community-based HIV testing intervention in non-medical settings for men who have sex with men
}

\author{
Karen Champenois, ${ }^{1}$ Jean-Marie Le Gall, ${ }^{2}$ Cédric Jacquemin,,${ }^{3,4}$ Sophie Jean, ${ }^{2}$ \\ Cyril Martin, ${ }^{2}$ Laura Rios, ${ }^{2}$ Olivier Benoit, ${ }^{2}$ Stéphanie Vermoesen, ${ }^{3,4}$ France Lert, ${ }^{5}$ \\ Bruno Spire, ${ }^{2,6,7}$ Yazdan Yazdanpanah ${ }^{1,8,9}$
}

To cite: Champenois $\mathrm{K}$, Le Gall J-M, Jacquemin C, et al. ANRS-COM'TEST: description of a community-based HIV testing intervention in non-medical settings for men who have sex with men. BMJ Open 2012;2:e000693. doi:10.1136/

bmjopen-2011-000693

- Prepublication history for this paper is available online. To view these files please visit the journal online (http:// dx.doi.org/10.1136/ bmjopen-2011-000693).

Received 29 November 2011 Accepted 27 February 2012

This final article is available for use under the terms of the Creative Commons Attribution Non-Commercial 2.0 Licence; see http://bmjopen.bmj.com

${ }^{1}$ ATIP-Avenir, Inserm U995, Lille, France

${ }^{2}$ AIDES, Pantin, France

${ }^{3}$ Inserm CIC9301, Lille,

France

${ }^{4} \mathrm{CHRU}$ de Lille, Lille, France

${ }^{5}$ Inserm U1018, Villejuif,

France

${ }^{6}$ Inserm U912 (SE4S), Marseille, France

${ }^{7}$ Université Aix Marseille, IRD, UMR-S912, Marseille,

France

${ }^{8} \mathrm{CH}$ de Tourcoing,

Tourcoing, France

${ }^{9}$ Université Lille-Nord de

France, Lille, France

Correspondence to Dr Karen Champenois; karen.champenois@gmail.fr

\section{ABSTRACT}

Objective: To describe a community-based HIV testing programme.

Design and setting: An intervention of HIV voluntary testing conducted in non-medical settings in four French cities.

Participants: Men who have sex with men (MSM). Intervention: Counselling and rapid HIV testing staffed by trained personnel from an HIV/AIDS community-based organisation.

Primary and secondary outcome measures: The population that has taken hold of the intervention and the satisfaction of participants. Data were collected on demographics, HIV testing history, sexual practices and satisfaction with the testing programme.

Results: 532 MSM were tested between February 2009 and June 2010, of whom $49(9 \%)$ were tested two or more times. 468 MSM (88\%) had casual male partners in the previous 6 months, and $152(35 \%)$ reported having unprotected anal intercourse with risky casual partners (HIV infected or HIV serostatus unknown). 159 men $(30 \%)$ had not been tested in the previous 2 years, and $50(31 \%)$ of whom had unprotected anal intercourse with risky casual partners. Among the 15 patients who tested positive $(2.8 \%), 12(80 \%)$ received confirmation and were linked to care (median CD4 cell count $=550 / \mathrm{mm}^{3}$ ). Satisfaction was high: $92 \%$ reported being 'very satisfied' with their experience. Steps of counselling and testing procedure were respected by testers and difficulties in handling tests were rare. Conclusions: This community-based HIV testing programme reached high-risk MSM, of whom a substantial proportion had not been tested lately. This novel service supplements pre-existing HIV testing services and increases access to HIV testing in high-risk groups.

\section{INTRODUCTION}

Until very recently in France, only physicians could prescribe, perform and provide the results of HIV tests. Although current HIV

\section{ARTICLE SUMMARY}

Article focus

- How extend testing facilities to reach and test for HIV more MSM and diagnose HIV-infected MSM earlier?

- The presence of peers and non-clinical staff members who address sexuality more openly and avoid medical jargon during counselling sessions could offset cultural barriers and reduce fears of HIV and associated stigma.

- The article describes an experimenta programme of community-based HIV testing: the population reached, the quality of the programme and the satisfaction of participants.

Key messages

- This community-based HIV testing and counselling programme reaches MSM with high-risk sexual behaviour, a substantial proportion of whom has not tested for HIV recently.

- Community testers are able to perform rapid HIV test into a comprehensive prevention approach in line with participant's life.

- $2.8 \%$ of participants tested positive. Infection was confirmed in all cases, $80 \%$ were linked to care. Cases were diagnosed at early stages of disease.

Strengths and limitations of this study

- This HIV testing and counselling programme is exclusively based on MSM community, and continuing the prevention counselling with the awareness of the HIV serostatus includes testing into a comprehensive prevention approach.

- Community-based HIV testing programmes may be attractive and efficient in large urban areas (like Paris), but perhaps less so in smaller cities, where an outreach approach may work better.

- The number of HIV diagnoses was small; the prevalence and median CD4 count among the few HIV-infected participants should therefore be interpreted with caution. 
testing rates in France rank second in Europe, ${ }^{1}$ roughly 50000 of an estimated 135000-170000 people infected with HIV remain unaware of their infection. ${ }^{2}$ Among people the most concerned by HIV, men who have sex with men (MSM) account for half of new HIV infections approximately. ${ }^{3}{ }^{4}$ The HIV incidence in MSM is 60-fold higher than in the overall population. ${ }^{3}$ Moreover, a recent study demonstrated that $32 \%$ of MSM were diagnosed at advanced stages of disease. ${ }^{5}$

The most significant barrier to early HIV testing is the absence of perception of risk for HIV ${ }^{6-8}$ In an effort to overcome this barrier, the French ministry of health recently recommended that physicians perform onetime routine voluntary HIV tests in the general population and annually in population groups at high risk of infection such as MSM. ${ }^{9}{ }^{10}$ However, barriers to HIV testing remain at the individual level: fear of the disease, its disclosure and subsequent social stigma, as well as poor access to HIV testing. ${ }^{6-8}$ In addition, the gay community highlight inappropriate counselling and some moralistic attitudes face to their sexual practices and testing habits in conventional testing services as barriers to regular HIV testing. ${ }^{11}$

The recent availability and acceptability of rapid HIV tests $^{12} 13$ offer an opportunity to implement new HIV testing strategies. A community-based HIV screening programme, for instance, may increase access in some populations by offering a more attractive and convenient location than doctor's offices. The presence of peers and non-clinical staff members who address sexuality more openly and avoid medical jargon during counselling sessions could also offset cultural barriers and reduce fears of HIV and associated stigma. Furthermore, some community-based organisations (CBOs) have been engaged in outreach prevention in which sexual practices, HIV exposures and testing are addressed. Continuing the prevention counselling with the awareness of the HIV serostatus could include testing in a comprehensive strategy of HIV exposure reduction.

In recent years, several European countries ${ }^{14-18}$ have begun implementing community-based HIV testing with rapid tests. They propose rapid testing in CBOs in large urban areas. The principle behind this strategy is the same than the one applied in developing countries where testing is conducted by lay counsellors from the community to facilitate access to testing to vulnerable populations. ${ }^{19}$ However, most of the reported programmes in developed countries involve medical staff, and although welcoming and support are conducted by community peers, HIV tests are performed by healthcare workers. To our knowledge, in Europe, the only ongoing community-based HIV testing programmes that do not involve medical staff is Checkpoint in Barcelona, Spain, ${ }^{20}$ and LASS in Leicester, England (http://www.lass.org.uk). However, data on these programmes (evaluation of an existing programme or set up into a study) have not yet been published.
The hypothesis was that a community-based HIV testing intervention may reach high-risk MSM, a high proportion of whom have not been tested lately; consequently, in addition to other existing HIV testing services, it may increase access to HIV testing in high-risk groups. The ANRS-COM'TEST Study describes a community-based HIV testing and counselling programme performed by peers in non-medical settings that targeted MSM. The purposes were to describe characteristics of the MSM who has taken hold of this programme and the satisfaction of participating MSM.

\section{METHODS}

\section{Ethics statement}

ANRS-COM'TEST Study was approved by the French Comité de protection des personnes Nord-Ouest III and the Agence française de sécurité sanitaire des produits de santé. All participants were informed of the study and had to sign a consent form to be included. The survey was anonymous.

\section{Intervention}

The community-based HIV testing was managed by AIDES, a French CBO that focuses on outreach and prevention among exposed population and notably MSM. Although not being healthcare workers, trained AIDES CBO staff members performed the whole testing procedure including pre- and post-test counselling, rapid HIV tests as well as delivery of test result (figure 1). Prior to HIV testing, testers spoke with participants about their sexuality, risk perceptions and sexual safety. Once the results were available, participants learnt their HIV status, as well as strategies to reduce sexual risk taking.

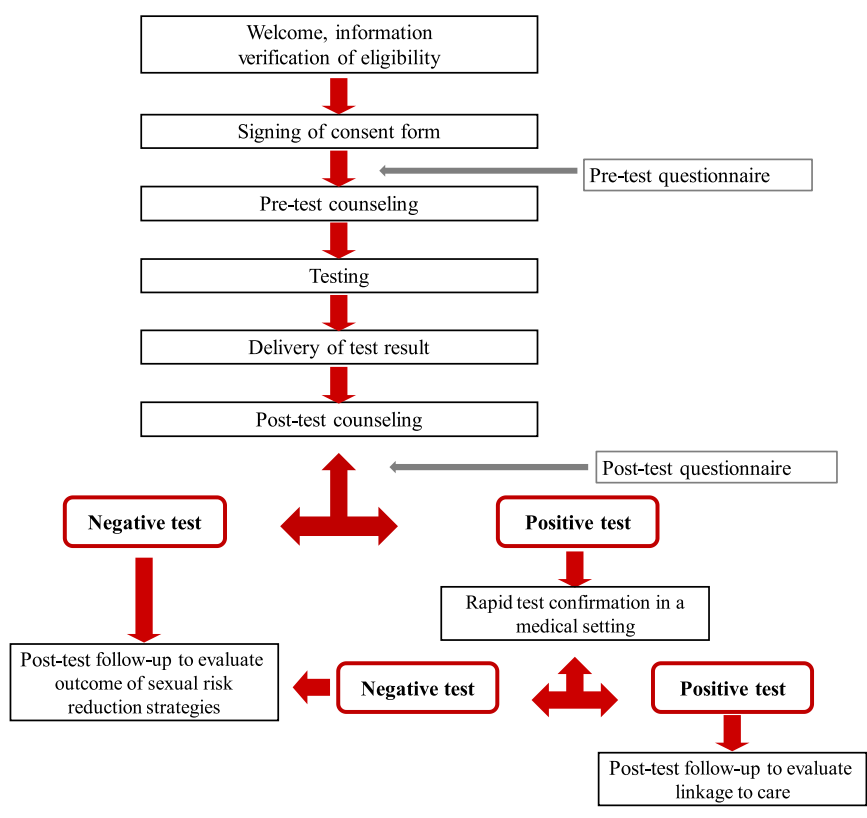

Figure 1 ANRS-COM'TEST Study diagram. 
AIDES CBO staff members were trained specifically in risk assessments, risk-reduction strategies and counselling using published motivational interview methods. ${ }^{21}$ They were also trained in performing the rapid HIV test, reading the test and delivering the result and referral for confirmatory test or other services if needed.

The VIKIA ${ }^{\circledR}$ HIV1/2 BioMérieux rapid HIV test kit (sensitivity: $99.8 \%$; specificity: $99.9 \%^{22}$ ) was used to analyse a self-drawn whole blood sample from the participant's fingertip. Results were available within $30 \mathrm{~min}$. Participants who tested positive were referred to HIV clinics for confirmatory blood tests and linkage to care.

The intervention offered HIV tests during $3 \mathrm{~h}$ sessions once or twice a week in the evening and/or on the weekend in the AIDES CBO locations in the French cities of Montpellier, Lille, Bordeaux and Paris. No appointment was required, and HIV tests were performed on a first-come first-served basis. We informed the MSM community about the intervention through communication campaigns (posters, flyers, web banners and ads) at commercial and non-commercial gay venues, as well as in gay websites, magazines and organisations. The study sites were the settings of the AIDES CBO. The possibility of performing an HIV test was, however, not advertised outside the setting to preserve confidentiality.

\section{Study population}

ANRS-COM'TEST exclusively targeted MSM. Eligibility for the study included age $\geq 18$ years and pursuit of HIV testing at one of the four participating AIDES CBO locations. MSM who reported potential exposure $\leq 48 \mathrm{~h}$ prior to enrolment were not included. Rather, they were immediately referred to medical settings for HIV testing and post-exposure prophylaxis.

One of the most important goals of the intervention evaluated in this study was to target MSM who are not regularly tested for HIV (or never tested). In the French 2004 Gay Press survey - a survey investigating lifestyle and sexual behaviours in MSM who read the gay press-17\% of MSM stated that they have never been tested for HIV in their life. Among those with at least a history of one HIV test, $27 \%$ stated that they were not tested in the previous 2 years. Based on these results, we therefore anticipated that $30 \%$ of MSM enrolled in our study would not have a history of HIV testing in the previous 2 years. We calculated the number of patients to be enrolled in this study to have a precision of $4 \%$ around this estimated point. The calculated sample size was 504 MSM; given the highest number of participants that could be tested by session in each centre, the enrolment time was estimated at approximately 1 year.

\section{Study outcomes}

The population that has taken hold of the intervention was described, in particular its demographic characteristics, HIV testing habits and sexual practices.

The satisfaction of the participants with the programme was collected just after the testing. The difficulties occurred in handling rapid tests, the respect of counselling and testing procedures and the proportion of participants tested positive who were linked to care were also assessed.

\section{Data collection}

Participants completed one questionnaire before and one after the test. The pre-test questionnaire assessed demographic characteristics, previous HIV testing history, sexually transmitted infections (STIs) diagnosis in the previous 6 months and sexual practices in the previous 6 months. Using a 4-point Likert scale, the posttest questionnaire assessed satisfaction with the testing experience, that is, satisfaction globally and with each step of counselling and testing procedure. It also assessed satisfaction during the interviews with counsellors, satisfaction with words used, items addressed and information learnt. Finally, it addressed stress and comfort of an HIV testing performed by peers in non-medical settings.

Staff members used a form that outlined every step of the intervention: welcome and description of the study, participant's signature of the consent form, major concerns to address during pre- and post-test interviews and difficulties faced at each step of HIV testing procedure. For every participant, staff members marked the completion of each step (done or addressed: yes/no/ partially) and mentioned any comments. This form was in particular used to identify problems faced during testing and counselling.

AIDES CBO staff members conducted face-to-face interviews with patients who were tested positive 3 months later to evaluate their linkage to care.

\section{Data analysis}

The main analysis was descriptive: medians and IQR were used to describe quantitative data, and numbers and proportions were used to describe qualitative data.

Some comparisons were performed between participants tested negative and positive, and participants retested during the study period at study sites and those were not retested. For this purpose, the Fisher exact test was used to compare proportions.

Statistical analyses were performed with SAS V.9.2 software (SAS Institute Inc.).

\section{RESULTS}

Overall, 598 men sought voluntary HIV testing at AIDES CBO involving locations. We excluded 66 participants. The three main reasons to not be included were (1) reported sex exclusively with women $(n=25)$, (2) women $(n=14)$ and (3) refused to participate due to the amount of time they should have spent for testing and research procedures (around $2 \mathrm{~h}, \mathrm{n}=10$ ). Among the 17 remaining men not enrolled in the study, 10 refused for different reasons (afraid of lack of confidentiality, no need to be tested for HIV, need time to think a possible participation) and the seven other were excluded 
because of age $<18$ years, a risk exposure $<48 \mathrm{~h}$ or they did not understand French speaking. The man who reported a potential HIV exposure $<48 \mathrm{~h}$ was referred to a post-exposure prophylaxis service.

We enrolled 532 MSM in the study and performed 592 tests; 49 participants $(9 \%)$ were tested two or more times throughout the study period. More than half of the tests were performed in Paris $(285 / 592,54 \%)$. Socio-demographic characteristics of participating men are shown in table 1. Although $94 \%$ of men defined themselves as MSM, $128(25 \%)$ stated that their sexual identity was unknown to their family and $64(13 \%)$ that they had not revealed it to anyone.

Of the 527 MSM who answered questions regarding their HIV testing habits, 368 (70\%) reported having been tested in the previous 2 years. Among these men, the median number of tests in the previous 2 years was two (IQR, 1-4) and the last test was performed for a median of 8 months (IQR, 4-14) prior to enrolment (table 2). Among the 159 MSM (30\%) who had not been tested in the previous 2 years, the last test was conducted for a median of 46 months (IQR, 34-62) before enrolment.

\begin{tabular}{|c|c|}
\hline Participant characteristics & Median (IQR) \\
\hline Age & $31(25-38)$ \\
\hline Participant characteristics & n $\left(\%^{*}\right)$ \\
\hline \multicolumn{2}{|l|}{ Sexual identity } \\
\hline Homosexual & $432(82)$ \\
\hline Bisexual & $66(12)$ \\
\hline $\begin{array}{l}\text { Heterosexual or did not want } \\
\text { to define themselves }\end{array}$ & $32(6)$ \\
\hline \multicolumn{2}{|l|}{ Homo/bisexual identity is } \\
\hline Accepted by everyone & $140(28)$ \\
\hline Unknown to everyone & 64 (13) \\
\hline Unknown to family $†$ & $128(25)$ \\
\hline Ever insulted because of sexuality & $106(20)$ \\
\hline \multicolumn{2}{|l|}{ Matrimonial status } \\
\hline Single & $367(69)$ \\
\hline In a free union with a man & $124(23)$ \\
\hline Married or in a free union with a woman & $26(5)$ \\
\hline Other & $13(3)$ \\
\hline \multicolumn{2}{|l|}{ Educational level } \\
\hline Above high school & $372(71)$ \\
\hline High school or below & $155(29)$ \\
\hline \multicolumn{2}{|l|}{ Professional status } \\
\hline Employed & $337(64)$ \\
\hline Unemployed & $92(17)$ \\
\hline Student & 99 (19) \\
\hline Sex worker & $16(3)$ \\
\hline \multicolumn{2}{|c|}{$\begin{array}{l}{ }^{*} \text { The study enrolled } 532 \text { men who have sex with men (MSM). } \\
\text { Percentages are calculated based on the number of respondents to } \\
\text { each question. For each question, there were less than five missing } \\
\text { data points ( }<1 \%) \text { f for questions regarding acceptance of } \\
\text { homosexuality and bisexuality, there were between } 22(4 \%) \text { and } 35 \\
(7 \%) \text { missing data points according to the question. } \\
\text { tParents and/or siblings. } \\
\text { fDivorced or separated from partner. }\end{array}$} \\
\hline
\end{tabular}

Nearly all participants (96\%) reported having had at least one male partner in the previous 6 months; $92 \%$ said that these were casual partners. The median number of casual partners within the last 6 months was 12 (IQR, 6-25). Overall, $152(35 \%)$ men reported having unprotected anal intercourse with casual male partners who were HIV infected or whose serostatus was unknown. Among MSM who were tested in the previous 2 years, $100(27 \%)$ had unprotected anal intercourse with casual partners who were HIV infected or whose serostatus was unknown (table 2). This proportion was $31 \%$ among participants who had not been tested in the last 2 years. During the prior 6 months, 415 men (78\%) stated using at least once recreational drugs before or during sex and 205 men (39\%) reported regular use of them. The recreational drugs the most used here were alcohol $(336 ; 65 \%)$, poppers $(236 ; 46 \%)$ and cannabis $(140 ; 27 \%)$.

The most frequent reasons for participating in ANRS-COM'TEST and seeking HIV testing were (1) reassurance $(86 \%),(2)$ routine testing $(42 \%)$ and (3) recent risky sexual exposures $(41 \%)$. Forty-nine men (9\%) returned to ANRS-COM'TEST Study sites to be retested. Of these, seven (14\%) returned more than twice. The median time between two tests among these participants was 4 months (IQR, 2.5-6.7). MSM who returned did not differ demographically from those who came only once, but a larger proportion of returners had tested for HIV within the previous 2 years (94\% vs $68 \%$, $\mathrm{p}<0.0001$ ).

Of the 532 participants, 15 (2.8\%; $95 \%$ CI $1.4 \%$ to $4.2 \%$ ) were tested positive (table 3). Among these, 12 $(80 \%)$ received confirmatory test results and linked to care and three $(20 \%)$ lost to follow-up. Their median CD4 count at diagnosis was $550 / \mathrm{mm}^{3}$ (IQR, 484-571). Among the 15 men with positive results, eight (57\%) had not been tested for HIV in the previous 2 years (vs $30 \%$ among HIV-negative men; $\mathrm{p}=0.03$ ).

We collected 514 post-test satisfaction questionnaires; $92 \%$ of participants who tested negative $(464 / 504)$ and $70 \%$ of those who tested positive $(7 / 10)$ reported being 'very satisfied' with the intervention. Three-quarter would recommend 'certainly' community-based HIV testing and counselling to a friend and 54\% of those who tested negative stated that they would choose 'certainly' the same venue in the future. The main reasons for which some patients were not 'very satisfied' $(43 ; 8 \%)$ were the amount of time spent at the testing facility (median, $2 \mathrm{~h}$, including a $45 \mathrm{~min}$ explanation of the study and questionnaires completion) and the hours during which testing was available. Among the 440 MSM who had reported to have performed HIV tests in the past, $55 \%$ found community-based HIV testing less stressful than traditional HIV testing, while only $5 \%$ found it more stressful. Eight-eight per cent found that testing in nonmedical settings offers a best welfare. More than $98 \%$ of participants attested they could address sexuality openly with peers and no one reported feeling judged. 
Table 2 Risk profile of the 532 ANRS-COM'TEST participants

\begin{tabular}{|c|c|c|}
\hline HIV test in the previous 2 years? & $\begin{array}{l}\text { No test } \\
n=159\end{array}$ & $\begin{array}{l}\geq 1 \text { test } \\
n=368\end{array}$ \\
\hline \multicolumn{3}{|l|}{ History of HIV testing in the previous 2 years* } \\
\hline Months since previous test, median (IQR) & $46(34-62)$ & $8(4-14)$ \\
\hline Number of tests in the previous 2 years, median (IQR) & 0 & $2(1-4)$ \\
\hline Casual male partners and sexual behaviour 6 months prior to testing, $\mathrm{n}(\%)$ & $132(83)$ & $333(90)$ \\
\hline Number of casual partners, median (IQR) & $11(5-20)$ & $14(6-30)$ \\
\hline Partners were HIV infected or serostatus was unknown, n (\%) & $123(77)$ & 307 (83) \\
\hline $\begin{array}{l}\text { Number of casual partners who were HIV infected or whose serostatus was } \\
\text { unknown, median (IQR) }\end{array}$ & $8(3-13)$ & $10(4-20)$ \\
\hline $\begin{array}{l}\text { Unprotected anal intercourse with partners who were HIV infected or whose } \\
\text { serostatus was unknownt, } \mathrm{n}(\%)\end{array}$ & $50(31)$ & $100(27)$ \\
\hline History of STIs in the previous 2 years, $\mathrm{n}(\%) \neq$ & $8(5)$ & $44(12)$ \\
\hline
\end{tabular}

From the testers' point of view, peers were satisfied from their new activities. The different steps of the 592 testing and counselling procedures performed were respected (more than $90 \%$ of completion for every step). Difficulties in handling tests were rarely reported $(<2 \%)$ by testers, except concerning self-drawn blood samples (19\%) and blood collection by testers (14\%). A second test had to be performed for eight of the 592 tests $(1.5 \%)$ because an insufficient amount of blood had been collected. The results of each of these second tests were negative. No other adverse or unexpected events were reported. During pre-test counselling, major concerns were not addressed rarely: risk perception in $4 \%$ of interviews, information about HIV transmission routes in $7 \%$ and the anticipation of test results in $8 \%$. During post-test counselling, the test result was not explained in $6 \%$ of cases, strategies for a better prevention was not discussed in $8 \%$ and information about STIs testing was not given in $10 \%$ of cases.

\section{DISCUSSION}

ANRS-COM'TEST was an HIV testing programme that targeted MSM and studied community-based HIV testing using rapid HIV tests. Counselling and testing were performed by community members who were not healthcare workers. The programme reached MSM who

Table 3 Clinical characteristics of men who have sex with men who tested positive for HIV

\begin{tabular}{lr}
\hline Positive rapid HIV test, $\mathrm{n}(\%)$ & $15(2.8)$ \\
Loss to follow-up, $\mathrm{n}(\%)$ & $3(20)$ \\
Confirmation of positive & $12(80)$ \\
rapid HIV test, $\mathrm{n}(\%)$ & \\
Linkage to care, $\mathrm{n}(\%)$ & $12(80)$ \\
CD4 count at diagnosis & $550(484-571)$ \\
(cells $\left./ \mathrm{mm}^{3}\right)$, median (IQR) & \\
\hline
\end{tabular}

reported high rates of risky sexual behaviour known to be risk factors of seroconversion for HIV. ${ }^{23-25}$ Sexual behaviours in this population is similar to that of MSM who attend commercial gay venues in Paris in whom HIV prevalence was estimated recently at $18 \% .^{26}$

A substantial proportion of men enrolled in this study had not been tested for HIV recently, even though they were at high risk of HIV infection. These results may suggest that community-based HIV testing programmes may be attractive and convenient for population groups that have not been reachable with traditional HIV testing methods as it has been shown recently by a community-based HIV testing programme in the UK. ${ }^{17}$ The authors demonstrated that MSM at the communitybased programme were less likely to have been tested previously compared with people who were seen at genitourinary medicine clinics.

The programme also reached MSM regularly tested. Moreover, although our study lasted only 12-17 months according to the city, almost $10 \%$ of participating men were tested twice or more. A community-based voluntary counselling and testing programme for MSM in Geneva has shown that the proportion of MSM who return for testing is likely to increase over time. ${ }^{15}$ The MSM who returned for testing in the COM'TEST programme were also tested significantly more often for HIV than men who came once. Increased availability and selection of HIV testing services may therefore encourage even those who already test regularly in traditional programmes to test more often, thereby moving HIV diagnoses to earlier in infection. In addition to community-based HIV testing, other HIV testing strategies such as home tests or tests available in pharmacies may also be interesting to supplements pre-existing HIV testing services and increases access to HIV testing in high-risk groups. ${ }^{27} 28$ However, additional data are needed on benefits and harms of these strategies. 
Counselling and testing were performed by community members who are considered as peers. Although they were not healthcare workers, they were able to handle tests correctly, deliver test results, refer men according to their test result and respect counselling and testing procedures along the whole study period. They added testing and awareness of HIV serostatus to comprehensive prevention counselling in line with participants' lives that is one of the added values in comparison with HIV testing in the healthcare system. The high rate of satisfaction in MSM who participated in this study also shows that community-based HIV testing and counselling was largely acceptable. Overall, participants reported feeling more comfortable with testing and counselling with peers. The Barcelona Checkpoint in Spain that is completely staffed by peers as ANRS-COM'TEST drawn the same conclusions. ${ }^{20}$ Reasons for not being satisfied of the programme were linked to the study part that was too long and imposed tight opening sessions. The study part may curb some men to come for testing; attendance may be higher in the real life.

In France, the HIV prevalence was 1.6\% among MSM who attended voluntary counselling and testing clinics ${ }^{29}$ and $2.2 \%$ in a community-based testing in Paris both run by medical staff. ${ }^{18}$ In our study, $2.8 \%$ of men tested positive for HIV, and all those who underwent confirmatory testing were found to be HIV infected. The HIV prevalence was high, and consistent with rates seen in other recent community-based HIV testing programmes in Europe. During the first year of implementation, these programmes found MSM prevalence rates of $2.4 \%$ in Geneva, Switzerland, ${ }^{15} 3.2 \%$ in Brighton, $\mathrm{UK},{ }^{17} 3.2 \%$ in Barcelona, Spain, ${ }^{20}$ and $5.2 \%$ in Amsterdam, the Netherlands. ${ }^{14}$ These results suggest again that community-based HIV testing programmes like ANRS-COM'TEST could reach MSM who are at high risk of HIV infection. MSM with an HIV-positive test have been tested less often in the previous 2 years than men with a negative test; this result suggests that also this programme could reach MSM at high risk who were not tested recently in other testing services.

A large proportion of those men who tested positive for HIV at AIDES CBO were referred and linked to care. They were diagnosed at early stages of the disease, with median CD4 counts of $550 / \mathrm{mm}^{3}$ - higher than previously seen in traditional testing programmes. Data from the French HIV surveillance system in 2009 demonstrate that $20 \%$ of MSM were diagnosed with CD4 counts $<200 / \mathrm{mm}^{3}$ and $62 \%$ had CD4 counts $<500 / \mathrm{mm}^{3}{ }^{2}{ }^{2} 4$ These results are consistent with the British study, which found a median CD4 count of $431 / \mathrm{mm}^{3}$ among MSM who were diagnosed in community-based programmes compared with $311 / \mathrm{mm}^{3}$ among those who were diagnosed in genitourinary medicine clinics. ${ }^{17}$ When HIV testing is performed by peers at CBOs, MSM who show evidence of repeated risky sexual behaviour may feel less judged than in a traditional HIV testing programme run by healthcare workers. This difference in attitude may lead MSM to check their serostatus more frequently and sooner after exposure, resulting in earlier diagnoses.

This study has several limitations. First, ANRSCOM'TEST was conducted in four French cities but more than half of the participants enrolled in Paris. Community-based HIV testing programmes may be attractive and efficient in large urban areas, but perhaps less so in smaller cities, where an outreach approach may work better. Second, we certainly underestimated the proportion of MSM who would return for regular testing at $\mathrm{CBOs}$ since the study duration was short and many participants found the time spent completing questionnaires too lengthy. Third, the quality was assessed with a form completed by the community staff. The completion rates of different steps of the testing and counselling procedure may be overestimated. Finally, the number of HIV diagnoses was small. The prevalence and median CD4 count among the few HIV-infected participants should therefore be interpreted with caution.

The ANRS-COM'TEST Study was an HIV testing and counselling programme exclusively based on MSM community. It showed first that this type of programme could reach high-risk MSM, of whom a substantial proportion had not been tested recently; second, peers testers involved in such programmes may have the capacity to perform the test into a comprehensive prevention approach; third, participants tested positive are at early stages of disease and that a high proportion of them are linked to care. The programme demonstrated that community-based HIV testing delivered by non-medical staff could increase access to and choice of HIV testing facilities, supplementing existing HIV testing programmes. Based on this study results, French ministry of health recently authorised community-based HIV testing by non-healthcare $\mathrm{CBO}$ workers $^{30}$ as a complementary HIV testing service in France. Community-based HIV testing programmes should also be assessed in other populations at high risk for HIV infection and late presentation to care, such as sub-Saharan African immigrants. ${ }^{31} 32$

Acknowledgements We gratefully acknowledge all the community counsellors who participated in ANRS-COM'TEST. Neither the intervention nor the study would have been possible without them. We also thank Véronique Doré for her support in all stages of the study.

Contributors KC, J-MLG, SJ, CM, LR, OB, FL, BS and YY contributed substantially to conception, design and feasibility of the study. KC and J-MLG wrote the protocol of the study and coordinated the study. SJ, CM, LR and OB contributed to acquisition of data, and CJ and SV were responsible of the management of the data. $\mathrm{KC}$ performed the statistical analysis and presented results. All authors participated to interpretation of results. $\mathrm{KC}$ and $\mathrm{YY}$ draft the article. All authors revised the manuscript critically for important intellectual content and approved the final version to be published.

Funding The study was supported by the French Agence Nationale de Recherches sur le Sida et les hépatites virales (ANRS, http://www.anrs.fr). The funders had no role in study design, data collection and analysis, decision to publish or preparation of the manuscript. 
Competing interests With the exception of YY, none of the authors report any association that might pose a conflict of interest. $Y Y$ has received travel grants, honoraria for presentation at workshops and consultancy honoraria from Bristol-Myers Squibb, Gilead, Glaxo-SmithKline, Merck, Pfizer, Roche and Tibotec.

Ethics approval Ethics approval was provided by French ethics committee: 'comité de protection des personnes' and AFSSAPS.

Provenance and peer review Not commissioned; externally peer reviewed.

Data sharing statement There are no unpublished data to share.

\section{REFERENCES}

1. Cazein F, Le Vu S, Pillonel J, et al. HIV testing activity in France, 2003-2009. Bulletin Epidémiologique Hebdomadaire 2010;45-46:451-4.

2. Yéni P. Rapport 2010. Prise en charge médicale des personnes infectées par le VIH. Recommendations du groupe d'experts. Paris: Médecine-Sciences. Flammarion, 2010.

3. Le Vu S, Le Strat Y, Barin F, et al. Population-based HIV-1 incidence in France, 2003-08: a modelling analysis. Lancet Infect Dis 2010;10:682-7.

4. Cazein F, Lot F, Pillonel J, et al. Surveillance of HIV/AIDS infection in France, 2009. Bulletin Epidémiologique Hebdomadaire 2010;45-46:467-72.

5. Delpierre C, Cuzin L, Lauwers-Cances V, et al. High-Risk groups for late diagnosis of HIV infection: a need for rethinking testing policy in the general population. AIDS Patient Care STDS 2006;20:838-47.

6. de Wit JB, Adam PC. To test or not to test: psychosocial barriers to HIV testing in high-income countries. HIV Med 2008;9(Suppl 2):20-2.

7. Deblonde J, De Koker P, Hamers FF, et al. Barriers to HIV testing in Europe: a systematic review. Eur J Public Health 2010;20:422-32.

8. Kellerman SE, Lehman JS, Lansky A, et al. HIV testing within at-risk populations in the United States and the reasons for seeking or avoiding HIV testing. J Acquir Immune Defic Syndr 2002;31:202-10.

9. Haute Autorité de Santé. Recommandations en santé publique Dépistage de l'infection par le VIH en France - Stratégies et dispositif de dépistage. 2009. http://www.has-sante.fr/portail/jcms/c_704257/ depistage-de-linfection-par-le-vih-en-france-modalites-de-realisationdes-tests-de-depistage (accessed 11 Feb 2011).

10. Yazdanpanah Y, Sloan CE, Charlois-Ou C, et al. Routine HIV screening in France: clinical impact and cost-effectiveness. PLoS One 2010;5:e13132.

11. Spire B, de Zoysa I, Himmich H. HIV prevention: What have we learned from community experiences in concentrated epidemics? J Int AIDS Soc 2008;11:5.

12. Spielberg F, Branson BM, Goldbaum GM, et al. Choosing HIV counseling and testing strategies for outreach settings: a randomized trial. J Acquir Immune Defic Syndr 2005;38:348-55.

13. Wurcel A, Zaman T, Zhen S, et al. Acceptance of HIV antibody testing among inpatients and outpatients at a public health hospital: a study of rapid versus standard testing. AIDS Patient Care STDS 2005;19:499-505.

14. Van Loon S, Koevoets W. More results on your topic rapid HIV testing in a one-hour procedure motivates MSM in the Netherlands to take the test. XV International AIDS Conference; 11-16 July 2004. Bangkok, Thailand: International AIDS Society (IAS).

15. Gumy C, Huissoud T, Balthasar $\mathrm{H}$, et al. Community-based voluntary counselling and testing (VTC) for men who have sex with men (MSM) in Geneva, Switzerland: 2005-2009 monitoring. International AIDS Conference; 18-23 July 2010. Vienna, Austria: International AIDS Society (IAS).
16. Schwappach DL, Bruggmann P. An integrated model of care to counter high incidence of HIV and sexually transmitted diseases in men who have sex with men - initial analysis of service utilizers in Zurich. BMC Public Health 2008;8:180.

17. Bailey AC, Roberts J, Weatherburn P, et al. Community HIV testing for men who have sex with men: results of a pilot project and comparison of service users with those testing in genitourinary medicine clinics. Sex Transm Infect 2009;85:145-7.

18. Rouzioux C, Le Tallec J, Kreplak G, et al. Frequent HIV testing in a community setting improves detection of acute and recent infections, among MSM in Paris, France (Checkpoint study). International AIDS Conference; 17-20 2011. Rome, Italy: International AIDS Society (IAS)

19. Sweat M, Morin S, Celentano D, et al. Community-based intervention to increase HIV testing and case detection in people aged 16-32 years in Tanzania, Zimbabwe, and Thailand (NIMH Project Accept, HPTN 043): a randomised study. Lancet Infect Dis 2011;11:525-32.

20. Pujol F, Meulbroek M, Saz J, et al. BCN checkpoint: three-year experience (2007-2009) of a Community Based Centre for MSM in Barcelona (Spain) shows high effectiveness in HIV detection. International AIDS Conference; 18-23 July 2010. Vienna, Austria: International AIDS Society (IAS).

21. Miller W, Rollnick S. L'entretien motivationnel. Aider la personne à engager le changement: Inter Editions-Dunod. Dunod, Paris, France, 2006.

22. Plantier J, Maniez M, Barin F, et al. Evaluation of a new rapid test: VIKIA HIV 1/2. AIDS 2008-XVII International AIDS Conference. Mexico: International AIDS Society (IAS), 2008.

23. Ostrow DG, Plankey MW, Cox C, et al. Specific sex drug combinations contribute to the majority of recent HIV seroconversions among MSM in the MACS. J Acquir Immune Defic Syndr 2009;51:349-55.

24. Koblin BA, Husnik MJ, Colfax G, et al. Risk factors for HIV infection among men who have sex with men. AIDS 2006;20:731-9.

25. Schwarcz S, Scheer S, McFarland W, et al. Prevalence of HIV infection and predictors of high-transmission sexual risk behaviors among men who have sex with men. Am J Public Health 2007;97:1067-75.

26. Velter A, Barin F, Bouyssou A, et al. HIV prevalence and HIV testing behaviour among men who attend commercial gay venues in Paris (France), PREVAGAY 2009 survey. Bulletin épidémiologique hebdomadaire 2010;45-46:464-7.

27. Carballo-Dieguez A, Frasca T, Dolezal C, et al. Will gay and bisexually active men at high risk of infection use over-the-counter rapid HIV tests to screen sexual partners? J Sex Res 2012. doi:10.1080/00224499.2011.647117

28. Rifà B, Guayta R, Barau M, et al. Early HIV detection through rapid tests in pharmacies. International AIDS Conference; 18-23 July 2010. Vienna, Austria.

29. Le Vu S, Semaille C. Dépistage anonyme et gratuit du VIH. Profil des consultants de CDAG en 2004. Institut de Veille Sanitaire, 2006

30. Arrêté du 9 novembre 2010 fixant les conditions de réalisation des tests rapides d'orientation diagnostique de l'infection à virus de l'immunodéficience humaine (VIH 1 et 2). 2010:20499. JORF n0266, texte $\mathrm{n}^{\circ}$ 19. http://www.legifrance.gouv.fr/affichTexte.do? cidTexte $=$ JORFTEXT000023093746\&dateTexte $=$ \&categorieLien $=$ id (accessed 11 Feb 2011)

31. Lanoy E, Mary-Krause M, Tattevin P, et al. Frequency, determinants and consequences of delayed access to care for HIV infection in France. Antivir Ther 2007;12:89-96.

32. Ndiaye B, Salleron J, Vincent A, et al. Factors associated with presentation to care with advanced HIV disease in Brussels and Northern France: 1997-2007. BMC Infect Dis 2011;11:11. 